\title{
Q Methodology and Rural Research
}

Josephine Previte

Post-doctoral Fellow

School of Advertising, Marketing and Public Relations

Faculty of Business

Queensland University of Technology

GPO Box 2434

BRISBANE QLD 4000

AUSTRALIA

Ph: 61731384203

Fax: 61731381101

Email: j.previte@qut.edu.au

Barbara Pini

School of Management

Faculty of Business

Queensland University of Technology

GPO Box 2434

BRISBANE QLD 4000

AUSTRALIA

Ph: $\quad 38641298$

Fax: $\quad 38641766$

Email: b.pini@qut.edu.au

Fiona Haslam-McKenzie

Curtin Business School

Graduate School of Business

Curtin University of Technology

78 Murray St

Perth WA 8000

Tel: (61 8) 92661087 (Mob) 0417098880

McKenzieF@gsb.curtin.edu.au 


\title{
Q Methodology and Rural Research
}

\begin{abstract}
Traditionally, rural scholarship has been limited in its methodological approach. This has begun to change in recent years, as rural researchers have embraced a range of different methodological tools. The aim of this paper is to contribute to greater methodological pluralism in rural sociology by introducing readers to a method of research that is rarely engaged in the field. That is, Q methodology. The paper describes the defining features of the approach as well as provides examples of its application to argue that it is a method that offers particular opportunities and synergies for rural social science research.
\end{abstract}




\section{Introduction}

Methodologically the field of rural studies has been dominated by what Paul Cloke (1997, p. 370) has described as a 'fetishism' with numeric data (see also Falk and Zhao 1989; Garkovick and Bell 1995; Tickamyer 2000). While it has been said that the 'straightjacket of positivism' has been less stringent in our own country of Australia because of the relative infancy of the discipline, statistical scholarship has also traditionally enjoyed hegemonic status (Lawrence 1997, p.34). Change, however, is now evident. This is recognised by Cloke (1997) who argues there has been a recent methodological shift in the discipline with scholars drawing on texts such as art, photographs and magazines as data as well as undertaking ethnographic and interpretive studies. Illustrative of this challenge to methodological convention is that work that has engaged participatory action methods, adopted new technologies to build research relationships across geographical distances, and questioned traditional research orthodoxies concerning validity and reliability (e.g. Simpson, Daws and Wood 2003; Kilpatrick and Loechel 2004; Stehlik 2004).

In this methodological paper we seek to make a contribution to this literature by detailing another approach to research that we believe could be of benefit in rural research. That is, Q methodology. The fact that the method appears to be little used by rural researchers is not unsurprising as it is a 'relatively little known form of research methodology’ more generally (Barry and Proops 1999, p.338). ${ }^{1}$ However, in this paper we argue that the nature of Q methodology is such that were it to become better known, it could be successfully applied to address rural research questions. To begin,

\footnotetext{
${ }^{1} \mathrm{Q}$ methodology texts stress this is beginning to change and provide a multitude of examples of the application of Q method across disciplines such as political science, education, communication studies, marketing, business management, medicine, psychology. The $\mathrm{Q}$ methodology journal, Operant Subjectivity provides further evidence of the widespread application of the technique.
} 
we provide some background on the method and outline the phases in its application. Following this we identify the epistemic affinities between the approach and the cultural turn in rural sociology. In concluding the paper we draw attention to the question of limitations of Q method. In using examples of previous Q methodology studies we highlight work in areas that may be of direct interest to rural researchers such as in natural resource management, policy, community development, social issues and marginalised groups ${ }^{2}$.

\section{Q Methodology: An overview}

Q methodology was developed by psychologist and physicist William Stephenson in the 1930s, and documented in his much-referenced book, The Study of Behavior: $Q$ technique and its Methodology (1953). Like all methods, Q methodology can be defined in different ways depending upon one’s epistemological and ontological perspective. Its aim is typically stated as being to study people’s own perspectives, meanings and opinions. However, for some scholars, considerable emphasis is given to the fact that Q methodology allows a 'scientific' study of these phenomena. For example, Goldman (1999, p.589) categorises Q methodology as the 'science of subjectivity' while McKeown and Thomas 1988, p.12) determine it to be ‘a method for the scientific study of human subjectivity'. This emphasis on the 'scientific' credentials of the method is reflective of Stephenson's own disciplinary and positivist background, and the values and beliefs of those who have traditionally sought to apply Q methodology.

\footnotetext{
${ }^{2}$ For a full report on our own Q study see Pini, Haslam-McKenzie and Previte (2007).
} 
British work by Billard (1999, p.357) has commented that there has been a shift away from describing Q methodology as a 'scientific focus on subjectivity towards a discursive and critical approach'. Elaborating on this theme Goldman (1999, p.592) has written that in this respect the 'self is not a categorical construct in Q, rather it is thoroughly contextual, discursive, and social. It is formative, emergent, and continent, an empirical abstraction prone to elaboration and understanding rather than reduction.' It is in these terms that we conceptualise and engage Q methodology, and suggest that it may open up possibilities for contemporary rural social researchers. We are aware, however, that rural researchers who have argued for methodological pluralism, and embraced qualitative approaches as an opportunity to move beyond hypothetico-deductive methods, may be discouraged from using Q methodology because of its quantitative features. Stenner and Stainton Rogers (2004) have labeled the method Qualiquantological to reflect its qualitative and quantitative features. We acknowledge that Q methodology’s quantitative factorization renders it an unusual qualitative research method (Curt 1994). Nevertheless, as qualitative researchers ourselves we are interested in Q method as it provides an opportunity to shift our focus from a particular individual narrative, to an analysis of the range of viewpoints that is 'shared' or favoured by a particular group of participants. As Watts and Stenner (2005, p. 71) contend, Q methodology’s group focus makes it an idea, ‘and noticeably more macroscopic’ complement to qualitative approaches. We will return to this and other advantages of Q method later in the paper, but now provide a brief overview of the process of the method.

\section{Q Methodology: How does it work?}


Q methodology can be explained as encompassing five key stages. The first stage involves identifying the particular 'discourse’ which is under investigation. In Q methodology a discourse refers to a set of shared beliefs, opinions, understandings or meanings that is held by a population. ${ }^{3}$ For example, the discourse under investigation by Fieldhouse (1986) was attitudes towards food and nutrition while Brown (1993) investigated as a discourse animal experimentation. The discourse in a Q study will, of course, be directly connected to one's research question. While quantitative researchers typically develop a set of hypotheses at the commencement of a study, Q researchers develop research questions because Q methodology is a research technique that neither tests its participants nor imposes meaning a priori. (Stainton Rogers 1995). Rather, meaning and significance of generated profiles in Q methodology are ‘attributed a posteriori through interpretation’ (Brown 1980, p. 54).

The second stage in the Q process is to move from the broader discourse to identify a 'concourse'. This refers to the range of issues that exist on a particular discourse or topic. In developing a concourse researchers may use either naturalistic or ready-made texts (McKeown and Thomas 1988). In her study of discourses about lesbianism Kitzinger used interviews with lesbian women to develop her concourse. Dell and Korotana (2000) also used interviews to obtain a sense of the discourse about domestic violence, but turned as well to the literature and media reports to develop their concourse. In early Q methodological work Stepheonson (1936) used more unusual stimuli including a Q set of bottled fragrances to investigate the hedonic value of different odours. In other research scholars have utilized a set of photographs

\footnotetext{
${ }^{3}$ Some Q methodologists working from a post-structural perspective have turned to Foucault's scholarship on discourse for a more robust definition of the term (e.g. Dryzek 1994; Dell and Korotana 2000).
} 
to represent different aspects of a discourse about forest sector development

(Swaffield and Fairweather 2000). More typically, however, methodologists have employed a Q set of statements. During concourse development researchers build up a statement set which identifies different, but recognizable assertions about the social phenomena being studied with the aim of being 'broadly representative of the opinion domain at issue' (Watts and Stenner, 2005, p. 75).

The third stage in the Q methodology process is to develop a Q sample or Q statement set from the concourse. Developing the Q set assists researchers in refining and setting the research question, which, in Q method, must be clearly defined before data collection commences. Watts and Stenner (2005) recommend developing straightforward questions, containing a single proposition. A clearly defined statement in the research question is required because it dictates the nature and structure of the Q set and acts as a ‘condition of instruction’ for participants during the actual sorting process. Therefore, a Q set reflects the complexity of the issue represented, as well as enables each participant to respond based on their individual experience.

Usually the concourse will be 'around three times the size of the aimed-for Q set, say 200 for an aimed-for Q set of 65' so this is quite an arduous process (Stainton Rogers 1995, p.185) The size of the statement set will vary, but typically it is between 30 and 60 statements (Thomas and Watson 2002, p.142). ${ }^{4}$ Time and practical constraints need to be considered when determining the size of the sample. Piloting is consequently recommended. Overall, researchers must ensure that they have covered the breadth of opinions or themes that may circulate about a discourse, but also ensure

\footnotetext{
${ }^{4}$ There are, of course, variations. Kitzinger (1986: p.154) suggests the range is more typically between 15 and 100. Indeed, some Q studies have used less than the stated 40 (Rosenthal 2001) while others have used more than the stated 60 (Williams Jacobson and Aaltio-Marjosola. 2001).
} 
they have avoided unnecessary duplication as well as under/over sampling. There is a variety of suggested Q sample design techniques in the literature for moving from the concourse to the Q sample including thematically coding statements and matching them to a matrix according to different dimensions of a discourse to create a structured sample. This is a technique Barry and Proops (1999) engaged in their study of sustainability discourses. Alternatively, in a process they describe as 'unstructured,' Steelman and Maguire (1999, p.366) used a naturalistic approach from interviews to identify five themes about national forest management: forests, wildlife, roads, water and recreation. They then selected statements to represent the full range of views about each of these five topics, editing for clarity and brevity. The number of statements about each of the five themes differed according to how important interviewees perceived them to be. Mckeown and Thomas (1988) argue the naturalistic Q sample reduces the risk of respondents misunderstanding and misinterpreting statement meaning because the sample has been drawn from participants with shared experiences, rather than derived from some external source.

The fourth stage after the development of the Q sample is asking participants to order the statements in a process that is called a Q sort. This is a ranking procedure which Brown (1980, p. 7) calls 'the technical means whereby data are obtained for factoring'. In practice, statements are typically written on small cards and sorted into piles in a quasi-normal distribution according to 'conditions of instruction' described by the researcher. For example, participants will be asked to respond according to whether they strongly agree (+6) or strongly disagree (-6) with an individual item in the Q set. Table 1 illustrates a distribution and number of items that can be assigned to a ranking position. In Q sorting this is identified as a 'forced-free' distribution, 
because it takes the form of a quasi-normal distribution that is symmetrical about the middle. Both the range and the distribution shape are arbitrarily designed to accommodate the number of statements chosen for the study (Addams 2000, p. 22). Typical Q studies use an 11 or 13 point scale, with possible ranking values from +6 or +5 for items that are 'more agreeable' in view of the participants, through ' 0 ' to -6 or -5 for items considered 'more disagreeable'. The point in this procedural step is to ensure that Q sorters discard statements that are irrelevant and retain those that best describe their opinions and experiences of the social phenomena being studied. Brown (1980, p. 22) explains that a participant completing a Q sort is always more emotive about statements scored '-6' than those scored ' 0 ' because statements placed by participants towards the 'middle' lack significance, compared to those statements placed at the extremes. In practice, Q sorting is an interactive process and the factors that emerge are 'operational definitions' of opinions, experiences and preferences of each individual (Brown 1980).

Table 1 Q Sort Ranking

\begin{tabular}{|c|c|c|c|c|c|c|c|c|c|c|c|c|}
\hline-6 & -5 & -4 & -3 & -2 & -1 & 0 & +1 & +2 & +3 & +4 & +5 & +6 \\
\hline & & & & & & & & & & & & \\
\hline & & & & & & & & & & & & \\
\hline \multirow[t]{6}{*}{ (2) } & \multirow[b]{2}{*}{ (3) } & & & & & & & & & & & \multirow[t]{6}{*}{ (2) } \\
\hline & & & & & & & & & & & (3) & \\
\hline & & (4) & & & & & & & & (4) & & \\
\hline & & & (5) & & & & & & \multirow[t]{3}{*}{ (5) } & & & \\
\hline & & & & (6) & & & & (6) & & & & \\
\hline & & & & & (6) & & (6) & & & & & \\
\hline
\end{tabular}

(8)

\begin{tabular}{ccccccccccccc}
\hline-6 & -5 & -4 & -3 & -2 & -1 & 0 & +1 & +2 & +3 & +4 & +5 & +6 \\
\hline \multicolumn{3}{c}{ Most disagree } & & & \multicolumn{8}{c}{ Most agree } \\
\end{tabular}

Because Q methodology emphasises individual subjectivity, traditional positivist sampling techniques, which focus on the need to generalise from the studied population using large sample sizes, are not relevant (Brown 1996). The participant 
sampling process is much more akin to the purposeful or strategic sampling characteristic of qualitative research (Stenner and Marshall 1995). Thus, researchers may select participants to obtain variety in particular characteristics such as age, education, occupation, sex, political persuasion, cultural background or other factors relevant to the study. This is illustrated in the study reported by Robbins and Krueger (2000), which examined discourses surrounding the establishment of a Northern Forest Lands Council. In this instance, the researchers deliberately solicited conservation activists as well as timber company representatives for their sample believing they would have disparate perspectives on the subject. While variation in sample size is evident in the literature, small samples are common. For example, in one study Goldman and Emke (1991) report using only a sample of 8. More typically however studies use between 30-40 Q sorters. A larger number of participants can be problematic, because they can negate complexities and fine distinctions which are essential features of qualitative techniques. Watts and Stenner (2005, p. 79) therefore argue that there is value in using smaller numbers and to sample participants strategically, 'especially if they seem likely to express a particularly interesting or pivotal viewpoint'.

The final stage of the process of Q methodology is analysis where subjects' responses are typically factor-analysed in order to identify patterns across individuals. ${ }^{5}$ This is distinguishable from the traditional survey R methodology, which is concerned with determining patterns across variables. ${ }^{6}$ Individuals who 'load' on the same factor

\footnotetext{
${ }^{5}$ Explanation of Q methodology's statistical analysis, which involves factor extraction, rotation and estimation has been described in detail in Brown (1980) and McKeown and Thomas (1988).

6 There has been significant debate about the differences between Q and R methodologies in the literature and we are not meaning to over-simplify this issue (see Durning 1999, p.404-405; Robbins and Krueger 2000, p.640; Brown, Durning and Selden 1999, p. 602). There is also considerable argument as to whether such a comparison is even necessary or justified.
} 
have sorted the statement items similarly and consequently will be those who have a similar discursive position. Others may differ. For example, in her study of a county dispute over a visitors’ convention bureau Maxwell (2000) identified two different perspectives - those who wanted to improve what was in existence and those who wanted an entire restructure. Statistical interpretation can contribute to elaborating the qualitative findings by identifying distinguishing statements for each idealized sort. A distinguishing statement is defined as one that is 'most different' from other statements when they are rank ordered in respect to each idealized Q sort. By identifying distinguishing statements Q researchers can create a ‘distinct picture' for each factor array (Shemmings, 2006, p. 154).

There are various computer software packages available to assist with data analysis including Q methodology specific packages (e.g. PQMethod which is freeware and can be downloaded from the web) and PCQ analysis software, which is windows based. Again, in the case of the county conflict, Maxwell (2000) engaged the PQMethod package to interrogate her data, identifying areas of consensus between the two factors or points of view, as well as delineating the areas of disagreement between the factors. Automation does not, of course, negate the importance of researcher analysis. Brown (1980) recommends researchers run from a seven-factor to two-factor solution before accepting a final solution. This process assists interpretation because the researcher is continually positing possible explanations for the factors until the best explanation can be developed. At a practical level, McKeown and Thomas (1988, pp. 52-53) suggest 'common sense offers the best counsel when 
determining the importance of actors, that is, their contextual significance in light of the problems, purposes, and the theoretical issues in the research project'.

The interpretive process in Q methodology is therefore guided by a 'series of summarized account' which is explicated in a factor array that exemplifies a particular group's point of view. Therefore, the input of subjective data, results in the production of 'objective structures'. Watts and Stenner (2005, p. 85) argue that this procedure reduces the ecological validity common to qualitative methods, but, at the same time, the presence of objective structures demands 'a great deal of the interpreting researcher'. A researcher's interpretations can also be verified by returning to participants for follow-up interviews (Brown, Durning and Selden 1999, p.625). A researchers should return only to those participants with a significant factor loading in the factor array. At this stage it is important to keep in mind that each factor array represents a group’s 'shared' viewpoint. Thus, interviewees do not have to ‘provide a veridical representation of a participant's own opinion' (Watts and Stenner 2005, p. 85). To further enhance accuracy and efficacy some Q methodologists conduct interviews during the Q sort process, asking participants to comment on their choices. These comments are recorded to facilitate analysis.

In concluding a Q methodology study the researcher thus has a map of subjectively expressed, socially organized semantic patterns of how participants conceptualise or think about an issue. Q methodologists cannot specify the frequency of an attitude or opinion, but they have knowledge of its existence as well as its characteristic features or dimensions. How this may be of benefit to rural social researchers is explored below. 


\section{Q Methodology and Rural Research}

In 1992 Chris Philo published an important article in the Journal of Rural Studies entitled 'Neglected Rural Geographies' in which he argued that the subject of rural social science has been narrowly constructed and defined. In both this initial paper and the responses it generated (Philo 1993; Murdoch and Pratt 1993; 1994), questions of identity, power, diversity and inequality were all brought to the fore, and debate was opened up, not just about what we studied as rural social scientists, but how we studied it. Informing this reflective critique was the growing influence of critical social and cultural theory, which was shifting the foundational ground upon which rural social science had been established. Central to this paradigmatic shift was the questioning of orthodoxies about knowledge creation, truth claims, objective reality and the essential subject, as well as the introduction of a nomenclature mobilising around notions such as discourse, subjectivity, power and agency.

Thus, over the decade of the 1990s we saw considerably different types of rural social science research emerge with new preoccupations and priorities. ${ }^{7}$ For example, social constructionist perspectives were adopted to challenge assumptions that there were pre-existing, known and stable categories such as the 'rural' (Jones 1995) or 'drought' (Stehlik, Gray and Lawrence 1999). Writers questioned scientific power to determine and name agricultural knowledge and gave space to farmers’ own knowledge creation and knowledge practices (e.g. Kloppenburg 1991; Hassenein and Kloppenburg 1995).

\footnotetext{
${ }^{7}$ We are not suggesting that concerns with neglected voices or indeed the question of voice in research practice emerged only in the early 1990s. Feminist social science researchers, for example, were canvassing issues of power and exploitation in research in the 1970s and 1980s, as well as attempting to give academic attention to the subjugated perspectives of women (e.g. Roberts 1981), What changed in the previous decade is that these concerns started to be addressed in mainstream rural publications and by larger numbers of writers, including male scholars.
} 
In other work rural researchers sought strategies to minimize their authorial status and the normative and hierarchical divisions between the object/subject (e.g. Liepins 1998; Pini 2003). At the same time, new collections of work emerged focusing on previously neglected voices in rural studies, and seeking new approaches for attending to the narratives of those deemed 'other’ (e.g. Cloke and Little 1997; Milbourne 1997; Phillips, Watt and Shuttleton 2000).

It is in this epistemic environment that we see Q methodology as offering particular opportunities for rural researchers. In other disciplinary fields the method has been successfully engaged by social constructionists, feminist scholars and action researchers. (e.g. John 1997; Kitzinger 1999; Shar 2001; Williams Jacobson and Aaltio-Marjosola 2001). ${ }^{8}$ These groups have been attracted to Q methodology for four key reasons, and it is these we believe may also be appreciated by many rural social science researchers currently grappling with the shift to culture in the discipline.

The first of the attractions of Q methodology for groups such as action researchers, social constructionists and feminists is its focus on the subjective experiences of participants, its emphasis on context, and its privileging of the everyday and local. As Brown (1986, p.73) has written, the 'first axiom of Q methodology is that it is the subjective self that is at the centre of all meaning'. Thus, what is of interest to Q methodology researchers is how actors come to know and make meaning and sense of

\footnotetext{
${ }^{8}$ Kitzinger (1999) also raises important issues for feminists seeking to use Q methodology which may also be relevant to other scholars whose work is politically oriented. She explains that she has found publishing from Q methodology studies problematic and that the methodology rather than the content of her writing too often becomes the key focus of attention. For these reasons she no longer uses $Q$ method.
} 
their worlds from their own perspectives and experiences. This rejection of 'a priori assumption' about what items may mean or what a group of items may mean is distinctly different from approaches that seek to fit the experiences of participants into pre-determined categories (Gallivan 1994, p.33). Thus, Q methodology will be of interest to the increasing number of rural researchers interested in listening to and recording rural participants’ own accounts in their own words, rather than simply speaking for, or about, rural people.

The second of the factors that has been seen to be particularly useful about Q methodology, and which we believe may speak to rural researchers, is its capacity to subvert the power of the researcher. In the first instance, as stated above, the researcher's usual monopoly on determining and defining terms and categories is circumvented in Q methodology. However, there is far more potential for democratising Q methodology according to Billard (1999). Her suggestions, which include developing the concourse collaboratively, administering the Q sort with selected participants and, analysing the data collectively, have all been trialled in a project on industrial democracy. She cites the benefits for participants as including the 'development of reflexivity, consciousness-raising, empowerment and locally situated understandings’ (Billard 1999, p.365).

The third of the reasons why we suggest Q methodology may be an appropriate approach for contemporary rural researchers is that it acknowledges how troubling are concepts such as ‘truth' and 'language'. Indeed, Q methodology, according to Kitzinger (1986, p.153), is not concerned with definitive truths but with recognising ‘the existence of numerous ‘truths' or multiple versions of reality and then to 
exploring the meanings and implications of each.' Similarly, Goldman (1999) posits that inherent in Q methodology's emphasis on subjectivities and the differences and plurality among/between subjectivities is a questioning of language as a simple reflection of reality, and a rejection of the presumption that there exists a singular observable and knowable world that we as researchers can document. It is because this circumspection fits comfortably with much contemporary rural social science theory that we see opportunities for Q methodology in rural research.

A related final factor, which has seen $\mathrm{Q}$ methodology taken up by different social/critical theorists and which we believe may make it attractive to rural researchers, is its capacity to assist us in developing knowledge that is less reductive in that it opens up multiplicity, complexity, tension and inconsistency in subjectivities and between subjectivities. This is a point saliently made by Robbins and Krueger (2000) in citing an example from a study of Iowa farmers by Wilson (1998) that showed a significant Q factor cluster in which two apparently contradictory items were held in agreement. While expressing anxiety about farm chemicals on their families, participants simultaneously claimed that having a large chemical company in their area was to their advantage. Robbins and Krueger (2000, p.644) highlight the importance of this contradiction:

Either claim alone might allow a simple story about perceptions of nature, capital, and family. But together, in curious combination, they reveal something more about the complex assembly of constructions that make up the point of view - and political subjectivity - of many farmers in late capitalism. 
In a more recent study Zografos (2007) also demonstrates the usefulness of Q methodology for producing more nuanced understandings of social phenomenon. A study of how stakeholders view the role of Development Trusts in regenerating rural Scotland reveals the contested nature of notions of rurality and how discourses of rurality can be mobilized to support particular positions. As Zografos (2007, p. 50) argues, the study is important in revealing 'the variability, contradiction and variety of representation and articulation of rural discourses'. Q approach was critical to exposing this discursive complexity.

There are, of course, other advantages of Q methodology cited in the literature just as there is a range of disadvantages. We have not canvassed all of these because many of them do not resonate with our own theoretical perspective. As with any method, what is enthused about as well as criticised is likely to be closely connected to one's own epistemological and ontological frameworks. For example, one of the key criticisms often levelled against Q methodology is that it is subjective, while at the same time proponents suggest it represents a much more objective way to garner knowledge than other qualitative methods. ${ }^{9}$ Such claims assume that obtaining value-free data is possible and that subjectivity is intrinsically negative. Like many of the rural researchers we described at the beginning of this section, we are much more cautious about the process of knowledge creation, as well as clearly more positive about the place of the subjective in this process. We acknowledge that those researchers more sympathetic to positivist or empiricist traditions would necessarily make different claims about the method. We have simply attempted to present a view of Q

\footnotetext{
9 In this respect, Q methodology has been described as incorporating the best of qualitative and quantitative methods or as a qualitative method for analysing qualitative data (eg. Gallivan 1994, p.36; Brown 1996, p.561).
} 
methodology that is consistent with our own theoretical orientation. This is an orientation that, we have argued, began to emerge within rural social science in the early 1990s, and that has now been adopted by numerous scholars. It is this group of researchers who may find Q methodology useful.

At the same time, it is important to highlight one criticism that is made of Q methodology that is largely a pragmatic rather than epistemic matter. We raise it because it is likely to be relevant to rural researchers working with geographically isolated and dispersed populations. This is that the method is time consuming and administratively difficult in that sorting has had to occur face to face (Kanim 2000). However, it is possible now to work through this process via the internet using Q sort administration Web application programs that can be downloaded for no cost (Thomas and Watson 2002). Alternatively, other Q methodology studies have successfully mailed statements to participants for sorting in following a path similar to a mailed questionnaire (Barchak 1984). These options may be open to rural researchers, but Brown (1989) reminds us that a 'feeling for the organism' is critical to Q methodology and thus creating distance between researcher and participant should be avoided.

\section{Conclusion}

The purpose of this paper has been to introduce rural social scientists to Q methodology. There is, of course, far more to be said about the method than could be detailed in this brief paper and a range of helpful resources is available to assist those 
interested in learning more about the method. ${ }^{10}$ Rather than list a range of possible 'topics' that could be investigated by rural researchers using Q methodology, we have chosen, instead, to focus on highlighting the synergies between the approach and current theoretical concerns in rural social science. Suggesting what to research seems unnecessary when one understands that Q methodology invites the potential for studying any aspect of human subjectivity. As the applications are endless, and the term ‘subjectivity’ itself is ‘in vogue’ as Brown has observed (1998, p.94), it may now be that Q methodology’s time has come in rural scholarship.

\footnotetext{
${ }^{10}$ In our own work we have found the Q methodology email discussion list particularly helpful. Send command to Listserv@;listserv,kent.edu.
} 


\section{References}

Addams, H. (2000) Q methodology. Pp. 14-40 in H. Addams, \& J. Proops eds., Social discourse and environmental policy: an application of $Q$ methodology (Cheltenham, UK: Edward Elgar) pp. 14-40

Barchak, L. J. (1984) Discovering communication paradigms with Q methodology: ferment or sour grapes? Operant Subjectivity 7 (4) pp. 115-130

Barry, J. and J. Proops (1999) Seeking sustainability discourses with Q methodology. Ecological Economics 28 pp. 337-345

Billard, S. (1999) How Q methodology can be democratized. Feminism and Psychology 9 (3) pp. 357-366

Brown, R.R. (1980) Political subjectivity: applications of Q methodology in political science (New Haven, CT: Yale University Press)

Brown, S. R. (1989) A feeling for the organism: understanding and interpreting political subjectivity. Operant Subjectivity $12 \mathrm{pp}$. 81-97

Brown, S. R. (1993) A primer on Q-methodology. Operant Subjectivity 16 pp. 91-138

Brown, S. R. (1998) Subjective science. Normal and abnormal (continued). Operant Subjectivity $21(3 / 4)$ pp. 92-111

Brown, S. R., Durning D. W., and S. Selden (1999) Q Methodology. Pp. 599-637 in G. J. Miller and M. O. L. Whicker, eds, The handbook of research methods in public administration (New York: Marcel Dekker)

Brown, S. R. (1986) Q technique and method: principles and procedures. Pp. 57-77 in W. Berry and M. S. Lewis-Beck, eds, New Tools for Social Scientists: Advances and Applications in Research Methods (Beverley Hills, Sage)

Brown, S. R. (1996) Q methodology and qualitative research. Qualitative Health Research 6 (4) pp. 561-567

Cloke, P. (1997) Country backwater to virtual village? rural studies and "the cultural turn". Journal of Rural Studies 13 (4) pp. 367-375

Cloke, P. and J. Little, eds (1997) Contested countryside cultures (London: Routledge)

Curt, B. (1994) Textuality and tectonics: troubling social and psychological science (Buckingham: Open University Press)

Dell, P. and O. Korotana (2000) Accounting for domestic violence: a Q methodological study. Violence against women 6 (3) pp. 286-310

Dryzek, J. S. (1994) Australian discourses of democracy. Australian Journal of Political Science 29 pp. 221-239

Durning D. W. (1999) The transition from traditional to postpositivist policy analysis: a role for Q-methodology. Journal of Policy Analysis and Management 18 (3) pp. 389-410

Falk, W. W. and S. Zhao (1989) Paradigms, theories and methods in contemporary rural sociology: a partial replication and extension. Rural Sociology 54 (4) pp. 588-600

Fieldhouse, P. (1986) Food and nutrition: customs and culture (London: Croom Helm)

Gallivan, J. (1994) Subjectivity and the psychology of gender: Q as a feminist methodology. Pp. 29-36 in Crozier, S. D., Gallivan, J. and V. M. Lalande, eds, Women, Girls and Achievement (North York: Captus University)

Garkovich, L. and A. M. Bell (1995) Charting trends in rural sociology 1986-1995. Rural Sociology 60 (4) pp. 571-584 
Goldman, I. (1999) Q methodology as process and context in interpretivism, communication and psychoanalytic psychotherapy research. The Psychological Record 49 pp. 589-604

Goldman I. and I. Emke (1991) Communication and Canadian Identity: a Qmethodological study. Canadian Journal of Communication 16 pp. 129-138

Karim, K. (2000) Q methodology - advantages and disadvantages of this research method. Journal of Community Nursing 35 (4) pp. 8-10

Hassenein, N. and J. Kloppenburg (1995) Where the grass grows again: knowledge exchange in the sustainable agriculture movement. Rural Sociology $60 \mathrm{pp}$. 721-40

John, I. (1997) Discursive construction of the relationship between theory and practice in psychology. Australian Psychologist 32 (2) pp. 86-92.

Jones, O. (1995) Lay discourses of the rural: developments and implications for rural studies. Journal of Rural Studies 11 pp. 35-49

Kanim K. 2000 Q methodology - advantages and the disadvantages of this research method. Journal of Community Nursing 15(4) pp. 8-12

Kilpatrick, S. and B. Loechel (2004) Interactional infrastructure in rural communities: matching raining needs and provision. Rural society 14 (1) pp. 4-21

Kitzinger, C. (1986) Introducing and developing Q as a feminist methodology: a study of accounts of lesbianism. Pp. 151-172 in S. Wilkinson, ed, Feminist social psychology: developing theory and practice (Philadelphia: Open University Press)

Kitzinger, C. (1999) Researching subjectivity and diversity: Q-methodology in feminist psychology. Psychology of Women Quarterly 23 pp. 267-276

Kloppenburg, J. (1991) Social theory and the de/reconstruction of agricultural science: local knowledge for an alternative agriculture. Rural Sociology $56 \mathrm{pp}$. $519-48$

Lawrence, G. (1997) Rural sociology - does it have a future in Australian universities? Rural Society 7 (1) pp. 29-36

Liepins, R. (1998) Fields of action: Australian women's agricultural activism in the 1990s. Rural Sociology 63 (1) pp. 128-156

Maxwell, J. P. (2000) Managing conflict at the county level: the use of Q methodology in dispute resolution and strategic planning. Public Administration Quarterly (Fall) pp.338-355

McKeown, B. and D. Thomas (1988) Q methodology (Newbury Park, CA: Sage)

Milbourne, P. (1997) ed Revealing rural 'others' (London: Pinter)

Murdoch, J. and A. Pratt (1993) Rural studies: modernism, post-modernism and the post-rural. Journal of Rural Studies 9 (4) pp. 411-27

Murdoch, J. and A. Pratt (1994) Rural studies of power and the power of rural studies: a reply to Philo. Journal of Rural Studies 10 (1) pp. 411-27

Phillips, R. , D. Watt and D. Shuttleton (2000) De-centring sexualities: politics and representation beyond the metropolis (London: Routledge)

Philo, C. (1992) Neglected rural geographies. Journal of Rural Studies 8 (2) pp. 193207

Philo, C. (1993) Post-modern rural geography? Ala reply to Murdoch and Pratt. Journal of Rural Studies 9 (4) pp. 429-36

Pini, B. (2003) Feminist methodology and rural research: reflections on a study of an Australian agricultural organisation. Sociologia Ruralis 43 (4) pp. 418-433 
Pini, B. Haslam-McKenzie, F. and Previte, J. (2007) Stakeholders, natural resource management and Australian rural local governments: A Q methodological study. Local Government Studies. Forthcoming.

Robbins, P. and R. Krueger (2000) Beyond bias? The promise and limits of Q method in human geography. Professional Geographer 52 (4) pp. 636-648

Roberts, H. ed (1981) Doing feminist research. (London: Routledge and Kegan Paul)

Rosenthal, C. S. (2001) Divided lives: revisiting considerations of the personal and political. Women and Politics 22 (1) pp. 37-62

Shar, J. (2001) Getting integration started: Q methodology action research. Community Practitioner 74 (9) pp. 335-338

Shemmings, D. (2006) "Quantifying” qualitative data: an illustrative example of the use of Q methodology in psychosocial research. Qualitative Research in Psychology 3 (2) pp. 147-165.

Simpson, L., L. Daws and L. Wood (2003) More than just an internet connection: building rural social capital through public access. Rural Society 13 (2) pp. 113-125

Stainton Rogers, W. (1991) Explaining health and illness: an exploration of diversity (London: Harvester Wheatsheaf)

Steelman, T. A. and L. A. Maguire (1999) Understanding participant perspectives: Qmethodology in national forest management. Journal of Policy Analysis and Management 18 (3) pp. 361-388

Stehlik, D. (2004) From 'snowball' to 'rhizome': a rethinking of method. Rural society 14 (1) pp. 36-45

Stehlik, D., I. Gray and G. Lawrence (1999) Drought in the 1990s: Australian farm families' experiences. Rural industries Research and Development Corporation Canberra 99 (14)

Stenner, P. and R. Stainton Rogers (2004) Q methodology and qualiquantology: the example of discriminating between emotions. Pp. 157-189 in Z. Todd, B. Nerlich, S. Mckeown, and D. Clark, eds, Mixing Methods in Psychology (London: Routledge)

Stainton Rogers, R. (1995) Q methodology. Pp. 178-192. in J. A. Smith, R. Harre, and L. Van Langenhove, eds, Rethinking methods in psychology (London: Sage)

Stephenson, W. (1953) The study of behaviour: Q technique and its methodology (Chicago: University of Chicago Press)

Stricklin, M. and J. Almedia (2001) PCQ: analysis software for Q-technique (Academic Edition) [Computer software]. Available at http://www.pcqsoft.com/ [7 June 2005].

Swaffield, S. R. and J. R. Fairweather (2000) Community perception of forest sector development on New Zealand east coast: likely and acceptable employment activities, infrastructure and landscape change. Research Report No. 248 (Canterbury, New Zealand: Lincoln University)

Thomas, D. M. and R. T. Watson (2002) Q sorting and MIS research: a primer. Communications of the Association of Information Systems 8 pp. 141-156

Tickamyer, A. R. (2000) From the editor. Rural Sociology 65 (2) pp. 179

Watts, S. and P. Stenner (2005) Doing Q methodology: theory, method and interpretation. Qualitative Research in Psychology 2 pp. 67-91

Williams Jacobson, S. and I. Aaltio-Marjosola (2001) Strong objectivity and the use of Q-methodology in cross-cultural research. Journal of Management Inquiry 10 (3) pp. 228-248 
Wilson, J. (1998) Agricultural perspectives in eastern Iowa: a comparison of organic and conventional producers using Q-methodology (Iowa City: University of Iowa, Department of Geography)

Zografos, C. (2007) Rurality discourses and the role of the social enterprise in regenerating rural Scotland. Journal of Rural Studies 23 (1) pp. 38-51.

\section{Acknowledgements}

The paper is based on a research project entitled 'Rural Local Governments and Natural Resource Management' funded by the Rural Industries Research and Development Corporation (RIRDC). We are grateful for their support. 